\title{
Sliding-wear resistance of pure near fully-dense B4C under lubrication with water, diesel fuel, and paraffin oil
}

Ortiz, Angel L. ; Leal, Victor Manuel Candelario; Borrero-López, Oscar ; Guiberteau, Fernando

Published in:

Journal of the European Ceramic Society

Link to article, DOI:

10.1016/j.jeurceramsoc.2017.10.040

Publication date:

2018

Document Version

Peer reviewed version

Link back to DTU Orbit

Citation (APA):

Ortiz, A. L., Leal, V. M. C., Borrero-López, O., \& Guiberteau, F. (2018). Sliding-wear resistance of pure near fully-dense B4C under lubrication with water, diesel fuel, and paraffin oil. Journal of the European Ceramic Society, 38(4), 1158-1163. https://doi.org/10.1016/j.jeurceramsoc.2017.10.040

\section{General rights}

Copyright and moral rights for the publications made accessible in the public portal are retained by the authors and/or other copyright owners and it is a condition of accessing publications that users recognise and abide by the legal requirements associated with these rights.

- Users may download and print one copy of any publication from the public portal for the purpose of private study or research.

- You may not further distribute the material or use it for any profit-making activity or commercial gain

- You may freely distribute the URL identifying the publication in the public portal 


\section{Accepted Manuscript}

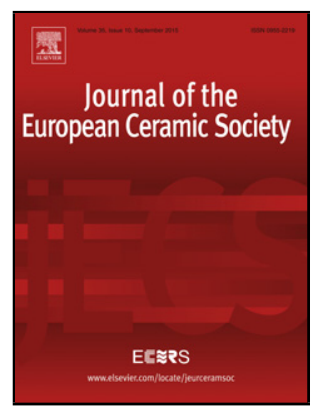

Title: Sliding-wear resistance of pure near fully-dense $\mathrm{B}_{4} \mathrm{C}$ under lubrication with water, diesel fuel, and paraffin oil

Authors: Angel L. Ortiz, Victor M. Candelario, Oscar Borrero-López, Fernando Guiberteau

PII:

DOI:

Reference:

To appear in:

Received date:

Revised date:

Accepted date:
S0955-2219(17)30720-3 https://doi.org/10.1016/j.jeurceramsoc.2017.10.040 JECS 11527

Journal of the European Ceramic Society

$$
\begin{aligned}
& 16-10-2017 \\
& 21-10-2017
\end{aligned}
$$

Please cite this article as: Ortiz Angel L, Candelario Victor M, Borrero-López Oscar, Guiberteau Fernando.Sliding-wear resistance of pure near fully-dense B4C under lubrication with water, diesel fuel, and paraffin oil.Journal of The European Ceramic Society https://doi.org/10.1016/j.jeurceramsoc.2017.10.040

This is a PDF file of an unedited manuscript that has been accepted for publication. As a service to our customers we are providing this early version of the manuscript. The manuscript will undergo copyediting, typesetting, and review of the resulting proof before it is published in its final form. Please note that during the production process errors may be discovered which could affect the content, and all legal disclaimers that apply to the journal pertain. 
Submitted to Journal of the European Ceramic Society, July 2017. Revised October 2017

\title{
Sliding-wear resistance of pure near fully-dense $\mathrm{B}_{4} \mathrm{C}$ under lubrication with water, diesel fuel, and paraffin oil
}

\author{
Angel L. Ortiz ${ }^{a, *}$, Victor M. Candelario ${ }^{\text {b,c }}$,

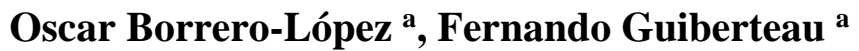 \\ a Departamento de Ingeniería Mecánica, Energética y de los Materiales, \\ Universidad de Extremadura, 06006 Badajoz, Spain. \\ ${ }^{\mathrm{b}}$ LiqTech International AS, Industriparken 22C, 2750 Ballerup, Denmark. \\ ${ }^{\mathrm{c}}$ Department of Energy Conversion and Storage, Technical University of Denmark, Ris $\varnothing$ \\ Campus, Frederiksborgvej 399, DK-4000 Roskilde, Denmark.
}

\begin{abstract}
$\underline{\text { Abstract }}$
The sliding-wear resistance of pure near fully-dense $\mathrm{B}_{4} \mathrm{C}$ is investigated, and the wear mode/mechanisms identified, under lubrication with water, diesel fuel, and paraffin oil. It is found that the wear is mild in the three cases, with specific wear rates (SWRs) of $10^{-16}-10^{-17}$ $\mathrm{m}^{3} / \mathrm{N} \cdot \mathrm{m}$. Nonetheless, the wear resistance of the $\mathrm{B}_{4} \mathrm{C}$ ceramic is one order of magnitude greater under oil lubrication $\left(10^{16} \mathrm{~N} \cdot \mathrm{m} / \mathrm{m}^{3}\right)$ than under water lubrication $\left(10^{15} \mathrm{~N} \cdot \mathrm{m} / \mathrm{m}^{3}\right)$, and twice as great for the specific case of paraffin oil than diesel fuel, attributable to the lubricant's viscosity. It is also found that the wear mode is always abrasion, and that the wear mechanisms are plastic deformation and localized fracture with grain pullout. However, in agreement with the macrowear data, the severity of the wear damage is lower under lubrication with paraffin oil, followed by diesel fuel, and lastly water. Finally, microstructural considerations are discussed with a view to enhancing the sliding-wear resistance of $\mathrm{B}_{4} \mathrm{C}$ triboceramics.
\end{abstract}

Keywords: $\mathrm{B}_{4} \mathrm{C}$; sliding wear; lubrication; spark-plasma sintering. 
* Corresponding author:

Angel L. Ortiz

Phone: +34 924289600 Ext: 86726

Fax: $\quad+34924289601$

E-mail: alortiz@ unex.es 


\section{Introduction}

There is continuous demand for ultra-hard ceramics for tribological applications. This is particularly the case for the carbide family (especially the covalent and interstitial carbides), which, in general, possess the greatest hardnesses of the advanced ceramics (oxide and nonoxide ceramics). $\mathrm{B}_{4} \mathrm{C}$, with its exceptional hardness (the hardest material known after diamond and cubic $\mathrm{BN}$ ), is therefore a promising candidate for the fabrication of triboceramics requiring durability and high wear resistance [1-9]. $\mathrm{B}_{4} \mathrm{C}$ is also exceptionally lightweight, an attribute that is key in movable or rotatory tribological applications where reduction of spurious weight is of prime importance. It is no surprise then that $\mathrm{B}_{4} \mathrm{C}$ is often used to fabricate blast nozzles, wheel dressing tools, bearings, mechanical seals, and cutting tools, to name some of its main industrial tribological applications.

The wear resistance of $\mathrm{B}_{4} \mathrm{C}$ has been the subject of earlier study. Thus for example, using the ball cratering test Moshtaghioun et al. [10] investigated microstructural effects on the abrasive wear of $\mathrm{B}_{4} \mathrm{C}$ ceramics fabricated by spark-plasma sintering (SPS), measuring specific wear rates (SWRs) of the order of $10^{-14} \mathrm{~m}^{3} / \mathrm{N} \cdot \mathrm{m}$ and finding that the wear resistance is dictated by the hardness, which is in turn controlled by the residual porosity without correlation with the grain size (in the range $120 \mathrm{~nm}-17.2 \mu \mathrm{m}$ ). Similarly, Turatti et al. [11] analyzed the abrasive wear of micrometre $\mathrm{B}_{4} \mathrm{C}$ ceramics fabricated by pressureless sintering with and without methylation of the starting powder and/or carbon additives (3.5 wt.\%), also measuring SWRs of the order of $10^{-14} \mathrm{~m}^{3} / \mathrm{N} \cdot \mathrm{m}$ and observing that methylation improves the wear resistance as a result of the greater hardness. Commercially available $\mathrm{B}_{4} \mathrm{C}$ ceramics processed by hot-pressing and tested under the same wear conditions also exhibited SWRs of the order of $10^{-14} \mathrm{~m}^{3} / \mathrm{N} \cdot \mathrm{m}$ [11]. Zorzi et al. [4] used the ball cratering test to compare the abrasive wear of $\mathrm{B}_{4} \mathrm{C}$ ceramics and of $\mathrm{B}_{4} \mathrm{C}-\mathrm{SiC}, \mathrm{B}_{4} \mathrm{C}-\mathrm{TiB}_{2}, \mathrm{~B}_{4} \mathrm{C}-\mathrm{B}$, and $\mathrm{B}_{4} \mathrm{C}-\mathrm{C}$ (4 wt.\% additives) composites prepared by 
pressureless sintering, again reporting SWRs of the order of $10^{-14} \mathrm{~m}^{3} / \mathrm{N} \cdot \mathrm{m}$ that decreased with increasing hardness. Likewise, $10^{-14} \mathrm{~m}^{3} / \mathrm{N} \cdot \mathrm{m}$ is also the order of magnitude of the SWR measured by Shipway et al. [12] for the abrasive wear of a superhard $\mathrm{B} 4 \mathrm{C}-3 \mathrm{wt} . \% \mathrm{C}$ composite (i.e., $36.3 \mathrm{GPa}$ hardness). Owing to their industrial use as nozzles, studies have been conducted as well on the impact erosion of $\mathrm{B}_{4} \mathrm{C}$ ceramics and composites under abrasive air-jets $[7,8]$ and water-jets [9], observing lower erosion rates with increasing hardness.

The two-body sliding wear of bulk $\mathrm{B}_{4} \mathrm{C}$ without external abrasion has, however, been less investigated, despite many triboceramics having the potential to operate under these contact conditions. Recently, Sonber et al. [13] studied the reciprocating sliding (ball-on-flat geometry) of hot-pressed $\mathrm{B}_{4} \mathrm{C}$ ceramics under dry un-lubricated conditions and a $\mathrm{WC}-\mathrm{Co}$ counterbody, reporting SWRs of the order of $10^{-15} \mathrm{~m}^{3} / \mathrm{N} \cdot \mathrm{m}$ that increased with increasing load (3-10 N load) and frequency $(10-15 \mathrm{~Hz})$. Also, Larsson et al. [14] measured SWRs for the self-mated sliding of $\mathrm{B}_{4} \mathrm{C}$ ceramics (pin-on-disk geometry) that decreased in the range $10^{-11}-10^{-14} \mathrm{~m} / \mathrm{N} \cdot \mathrm{m}$ with increasing relative humidity (in the range $20-100 \%$ ). Clearly, more tribological studies are still needed to expand the existing understanding of the sliding wear performance of $\mathrm{B}_{4} \mathrm{C}$ ceramics and composites under different operating conditions, including the identification of the dominant wear damage mechanisms.

With these premises in mind, in the present study we investigated the lubricated sliding wear of a pure near fully-dense $\mathrm{B}_{4} \mathrm{C}$ ceramic fabricated by SPS, which is currently being used to prepare $\mathrm{B}_{4} \mathrm{C}$ ceramics and composites without sintering additives [15-19]. In particular, the tribological performance was evaluated and the wear damage mechanisms identified under full lubrication with water, paraffin oil, and diesel fuel. Water was selected because, being cheap, abundant, and environmentally friendly, it is a widely used liquid lubricant with a high cooling 
capacity. Paraffin was chosen because oil-based lubricants are also widely used since they are less reactive, have longer durability, and better performance/lubricity, and are still safe, abundant, cost-affordable, and environmentally acceptable. Finally, diesel fuel was included in this comparative wear study because there is a growing interest in replacing metals by ceramics in many diesel engine tribocomponents to enhance the overall engine efficiency and performance.

\section{Experimental procedure}

The starting material was a commercially available submicrometric powder of $\mathrm{B}_{4} \mathrm{C}$ (Grade HD 20, H.C. Starck, Germany). This powder has been characterized in detail elsewhere $[19,20]$, concluding that (i) the particles have an average size of $\sim 0.6 \mu \mathrm{m}$ with an equiaxed and faceted morphology, and (ii) apart from $\mathrm{B}_{4} \mathrm{C}$ there are also $\mathrm{H}_{3} \mathrm{BO}_{3}$ and graphite impurities. The $\mathrm{B}_{4} \mathrm{C}$ powder was densified by SPS (SPS510CE, SPS Syntex Inc., Japan) in a dynamic vacuum atmosphere at a temperature of $1800{ }^{\circ} \mathrm{C}$ for 3 min under $75 \mathrm{MPa}$ pressure, with a heating ramp of $100{ }^{\circ} \mathrm{C} \cdot \mathrm{min}^{-1}$. After the completion of the SPS cycle, the pressure was released and the electrical power was shut off to allow rapid cooling (i.e., in 1-2 min) to room temperature. The resulting $\mathrm{B}_{4} \mathrm{C}$ ceramic was broken, and its fracture surface was observed by scanning-electron microscopy (SEM; Quanta 3D FEG, FEI, The Netherlands). Its surface was also polished to 1- $\mu$ m finish using conventional ceramographic methods, and its hardness was evaluated by Vickers indentation tests (MV-1, Matsuzawa, Japan) at 9.81 N load (ten indentations).

The sliding-wear tests were done in the ball-on-three-disks geometry under total lubrication conditions with the tribocouple fully immersed in water, paraffin oil, or diesel fuel. A commercial bearing-grade $\mathrm{Si}_{3} \mathrm{~N}_{4}$ ball (NBD 200, Cerbec, USA) of radius $6.35 \mathrm{~mm}$ was used to 
apply a normal contact load of $250 \mathrm{~N}$, with a rotation speed of $100 \mathrm{rpm}$ (corresponding to a sliding velocity of $\sim 0.047 \mathrm{~m} / \mathrm{s}$ ). The wear tests were interrupted at intervals to evaluate the size of the wear scar on the $\mathrm{B} 4 \mathrm{C}$ disks by optical microscopy, from which worn volumes were computed [21] to thus construct the wear curve (i.e., linear plot of the main worn volume vs. sliding distance) and to determine steady-state wear rates and therefore steady-state specific wear rates ${ }^{\ddagger}$. Finally, the wear damage on the $\mathrm{B}_{4} \mathrm{C}$ disks at the microstructural level was observed by SEM.

\section{$\underline{\text { 3. Results and discussion }}$}

Fig. 1 shows a representative SEM image of the $\mathrm{B}_{4} \mathrm{C}$ ceramic fabricated here by SPS $\left(1800{ }^{\circ} \mathrm{C}\right.$ for $3 \mathrm{~min}$ under $\left.75 \mathrm{MPa}\right)$. As can be seen, it has a fine-grained microstructure and is near fully-dense. Specifically, the average grain size is $\sim 0.6 \mu \mathrm{m}$, and the residual porosity is less than $5 \%$. The absolute density measured by Archimedes' method is $\sim 2.395 \mathrm{~g} / \mathrm{cm}^{3}$, which confirms the near-full densification (i.e., relative density of $\sim 95 \%$ ). Fig. 2 shows the XRD pattern of this $\mathrm{B}_{4} \mathrm{C}$ ceramic. As expected from the composition of the starting powder, it is essentially $\mathrm{B}_{4} \mathrm{C}$ (majority phase) with some residual $\mathrm{B}_{2} \mathrm{O}_{3}$ and $\mathrm{C}$ (very minority phases). The hardness of this $\mathrm{B}_{4} \mathrm{C}$ ceramic is $\sim 29 \pm 1 \mathrm{GPa}$.

Fig. 3 shows the worn volume (macro wear) as a function of the sliding distance for the $\mathrm{B}_{4} \mathrm{C}$ ceramic, as determined from the ball-on-three-disks tests with water, diesel fuel, and paraffin oil lubrication. It can be seen that in the three cases the wear volume increases linearly with increasing sliding distance, indicative of steady-state wear. Moreover, for every sliding distance, the wear volume is significantly greater in the specimen tested under water lubrication,

\footnotetext{
${ }^{*}$ In the steady-state wear stage, the wear volume $(V)$ follows the relationship $V=w_{R} \cdot d$, where the constant $w_{R}$ is the wear rate and $d$ is the sliding distance. The specific wear rate (SWR) is defined as $S W R=w_{R} / P$, where $P$ is the applied normal load per disk.
} 
followed by the specimen tested under diesel fuel lubrication, and lastly by the specimen tested under paraffin oil lubrication. Indeed, the wear rates, calculated from linear fits to the wear data in Fig. 3, are $5.1 \cdot 10^{-14} \pm 1.8 \cdot 10^{-15}, 3.6 \cdot 10^{-15} \pm 1.7 \cdot 10^{-16}$, and $1.72 \cdot 10^{-15} \pm 1.7 \cdot 10^{-16} \mathrm{~m}^{3} / \mathrm{m}$ under water, diesel fuel, and paraffin oil lubrication, respectively, so that the corresponding SWRs are calculated to be $8.6 \cdot 10^{-16} \pm 3.0 \cdot 10^{-17}$ (water), $6.0 \cdot 10^{-17} \pm 2.8 \cdot 10^{-18}$ (diesel fuel), and $2.9 \cdot 10^{-17} \pm 2.9 \cdot 10^{-18}$ (paraffin oil) $\mathrm{m}^{3} / \mathrm{N} \cdot \mathrm{m}$. These SWR values indicate mild wear at a macroscopic level in the three cases, which is characteristic of ultra-hard ceramics tested under lubricated ball-on-three-disk contact [22-24]. This supports the suitability of the present $\mathrm{B}_{4} \mathrm{C}$ ceramic as tribomaterial, at least under proper lubrication. Nonetheless, the wear resistance of the $\mathrm{B}_{4} \mathrm{C}$ ceramic is one order of magnitude greater when the contact is lubricated with oils $\left(1.7 \cdot 10^{16}\right.$ and $3.4 \cdot 10^{16} \mathrm{~N} \cdot \mathrm{m} / \mathrm{m}^{3}$ for diesel fuel and paraffin oil, respectively) than with water $\left(1.2 \cdot 10^{15}\right.$ $\mathrm{N} \cdot \mathrm{m} / \mathrm{m}^{3}$ ), and is two twice as great if the oil is specifically paraffin oil than it is diesel fuel. These trends are also evident from the mere visual comparison of the SEM images of the wear damage induced at the mesostructural scale under the different lubricants - as can be seen in Fig.4, the differences in the wear-scar size are (i) vast when the lubricant is water, and (ii) smaller between the two lubricant oils.

Figs. 5-7 show SEM images representative of the wear damage at the microstructural scale. In particular, two types of micro wear markings can be observed in Figs. 4-7 under each of the three lubricants: (i) scratches, due to plastic deformation caused by the indentation and sliding of sharp asperities of the counterbody ball and/or dislodged sharp particles (from the ball and/or specimen) trapped under the contact [25]; and (ii) pitted regions, which correspond to grain pullout from the subsurface. Grain pullout is the result of fracture from plasticity-induced stresses acting on both pre-existing defects (such as flaws at grain boundaries and pores) [26] 
and cracks which nucleate within (shear cracks) or at the edges (median and lateral cracks) of the plastic zone [25]. In all cases, the pitted regions in which grain pullout is observed are relatively shallow (that is, material loss is confined to the region immediately below the surface), which is entirely consistent with SWR values characteristic of mild wear at the macro-scale. These lubricated sliding-wear mechanisms are characteristic of abrasive wear of ceramics. Nonetheless, the specimens tested in water contain relatively more scratches, and those are also wider than the scratches observed in the specimens tested in oils (diesel fuel and paraffin oil). In addition, the specimens tested in water contain more pitted regions, and these are also larger and extend somewhat deeper below the surface than in the specimens tested in oils. Similarly, the specimens tested in diesel fuel contain more and wider scratches, as well as larger and deeper pitted areas than the specimens tested in paraffin oil, but the difference in wear damage is less patent than in the oil vs water case. Finally, it should be noted that despite water being a potentially reactive lubricant, the SEM images of the specimens tested in water do not show evidence of triboreactions under the loading conditions used in this study.

Wear at the macroscopic scale is the result of cumulative wear processes at the microscopic scale [25]. In this context, the wear volumes measured in the $\mathrm{B}_{4} \mathrm{C}$ ceramic are qualitatively consistent with the microscopic observations in the sense that the specimens tested in water show far greater macro-wear than the specimens tested in oils as a result of a greater number of wider scratches, and larger pitted regions. This also applies to the cases of the specimens tested in diesel fuel and paraffin oils. Given that water does not induce triboreactions here, the greater wear under water lubrication is ultimately due to the lower viscosity of water compared with the oils - i.e., 1 (water), 3.8 (diesel fuel), and 34 (paraffin oil) cSt -which allows for closer contact between the asperities of the sliding sphere and the specimens in the 
former case. The occurrence of more severe micro-contacts in turn results in (i) increased plastic deformation damage, and (ii) attendant increases in the extent of subsurface precursor damage in the form of shear, median, and/or lateral cracks. The former is consistent with the wider scratches observed in the specimens tested in water, and the latter increases the probability of crack propagation and coalescence, which is consistent with the larger size of the pitted regions in the water tests. The same argument holds in explaining the greater wear under diesel fuel lubrication in relation to the paraffin oil lubrication [27], with diesel fuel having lower viscosity than paraffin oil, i.e., 3.8 (diesel fuel) vs 34 (paraffin oil) cSt.

It is important to note that the severity of the micro-contacts is controlled not only by the lubricant, as proved by this study, but also by the applied load and the presence of third body abrasives. Indeed, higher viscosity lubricants and/or very low loads can result in sub-threshold micro-contacts, that is, without attendant sub-surface cracking [28]; in this case, plasticdeformation controlled, milder wear is expected. On the other hand, a lower viscosity lubricant, and/or higher loads and/or the presence of sharp particles under the contact (third body abrasion) will result in increased cracking around the micro-contacts; in this case, more severe wear will ensue. This is indeed the case of previous tests conducted in $\mathrm{B}_{4} \mathrm{C}$ ceramics by others [4,10-12], in which, despite a relatively low applied load (a few newtons or less), SWR values of the order of magnitude of $10^{-14}-10^{-15} \mathrm{~m}^{3} / \mathrm{N} \cdot \mathrm{m}$, greater than those measured in this study, were obtained due to the presence of abrasive hard particles under otherwise milder contact conditions than the ones used here.

Further improvements in sliding-wear resistance beyond the tribosystem optimization can be obtained via microstructural control of the $\mathrm{B}_{4} \mathrm{C}$ ceramics. Specifically, reducing the residual porosity is key to achieving $\mathrm{B}_{4} \mathrm{C}$ ceramics with super-high hardness (i.e., >30 GPa), and 
therefore with lower SWRs [29]. Note that it has been demonstrated recently that the SWR of B4C ceramics, also fabricated by SPS, increases markedly by $\sim 30$ and $50 \%$ for residual porosities of $\sim 1$ and 5\%, respectively [10]. This same trend has also been observed in $\mathrm{ZrC}$ ceramics, confirming that, in terms of wear resistance, the use of sintering additives is more convenient than an incomplete densification [24]. Additionally, reducing the grain size should also result in greater hardness [26,30], and therefore in lower SWRs [29]. This has been validated in other advanced ceramics [22,24,26,27,29,31-34], although in the $\mathrm{B}_{4} \mathrm{C}$ triboceramics the grain size effect is secondary to the residual porosity effect [10].

\section{Conclusions}

We have fabricated a pure near fully-dense $\mathrm{B}_{4} \mathrm{C}$ ceramic ( 5\% porosity) by SPS $\left(1800{ }^{\circ} \mathrm{C}\right.$ for 3 min under $75 \mathrm{MPa}$ ), and evaluated its tribological response (i.e., measurement of the wear resistance and identification of the wear mode/mechanism) under sliding contacts lubricated with water, diesel fuel, and paraffin oil. Based on the results and analyses, the following conclusions can be drawn:

1. Under the sliding contact conditions used (load and lubricants), the wear of the present $\mathrm{B}_{4} \mathrm{C}$ ceramic is mild, with SWRs of order of magnitude between $10^{-16}$ and $10^{-17} \mathrm{~m}^{3} / \mathrm{N} \cdot \mathrm{m}$. It is thus suitable for use in tribological applications, at least under proper lubrication.

2. The sliding-wear resistance of this $\mathrm{B}_{4} \mathrm{C}$ ceramic is one order of magnitude greater under oil lubrication $\left(1.7 \cdot 10^{16}\right.$ and $3.4 \cdot 10^{16} \mathrm{~N} \cdot \mathrm{m} / \mathrm{m}^{3}$ for diesel fuel and paraffin oil, respectively) compared to water $\left(1.2 \cdot 10^{15} \mathrm{~N} \cdot \mathrm{m} / \mathrm{m}^{3}\right)$, and is twice as great for the specific case of paraffin oil than diesel fuel, which is attributable to the lubricant's viscosity. 
3. Regardless of the lubricant, the lubricated sliding-wear mode of this $\mathrm{B}_{4} \mathrm{C}$ ceramic is abrasion and the wear mechanisms are plastic deformation and localized fracture with grain pullout. The severity of the wear damage at the microstructural scale and of the macro wear (i.e., worn volumes or wear-scar size) are correlated.

Acknowledgements This work was supported by the Ministerio de Economía y Competitividad (Government of Spain) and FEDER Funds under Grant nº MAT2016-76638-R. Financial support from the Junta de Extremadura under Grant $\mathrm{n}^{\circ}$ GR15078, also co-financed with FEDER Funds, is gratefully acknowledged as well. 


\section{References}

1) F. Thevenot, Boron carbide—a comprehensive review, J. Eur. Ceram. Soc. 6 (4) (1990) $205-225$.

2) A.K. Suri, C. Subramanian, J.K. Sonber, T.S.R-Ch. Murthy, Synthesis and consolidation of boron carbide: a review, Int. Mater. Rev. 55 (1) (2010) 4-40.

3) V. Domnich, S. Reynaud, R.A. Haber, M. Chhowalla, Boron carbide: structure, properties, and stability under stress, J. Am. Ceram. Soc. 94 (11) (2011) 3605-3628.

4) J.E. Zorzi, C.A. Perottoni, J.A.H. da Jornada, Hardness and wear resistance of B 4 C ceramics prepared with several additives, Mater. Lett. 59 (23) (2005) 2932-2935.

5) W. Lin, N. Feng, L. He, Wear properties of reaction sintered $\mathrm{B}_{4} \mathrm{C}$ composites, Adv. Mater. Res. 152-153 (2011) 883-886.

6) P.T.B. Shaffer, Engineering properties of carbides, in: S.J. Schneider (Ed.), ASTM Engineered Materials Handbook. Vol. 4-Ceramics and Glasses, Materials Park, Ohio, 1991, pp. 804-811.

7) S. Junlong, L. Changxia, T. Jin, F. Baofu, Erosion behavior of $\mathrm{B}_{4} \mathrm{C}$ based ceramic nozzles by abrasive air-jet, Ceram. Int. 38 (8) (2012) 6599-6605.

8) J. Deng, Erosion wear of boron carbide ceramics nozzles by abrasive air-jets, Mater. Sci. Eng. A 408 (1-2) (2005) 227-233.

9) K.A. Schwetz, L.S. Sigl, J. Greim, H. Knoch, Wear of boron carbide ceramics by abrasive waterjets, Wear 181-183 (Part 1) (1995) 148-155.

10) B.M. Moshtaghioun, D. Gomez-Garcia, A. Dominguez-Rodriguez, R.I. Todd, Abrasive wear rate of boron carbide ceramics: influence of microstructural and mechanical aspects on their tribological response, J. Eur. Ceram. Soc. 36 (16) (2016) 3925-3928. 
11) A.M. Turatti, A.S. Pereira, Wear resistant boron carbide compacts produced by pressureless sintering, Ceram. Int. 43 (11) (2017) 7970-7977.

12) P.H. Shipway, J.J. Hogg, Wear of bulk ceramics in micro-scale abrasion - the role of abrasive shape and hardness and its relevance to testing of ceramic coatings, Wear 263 (712) (2007) 887-895.

13) J.K. Sonber, P.K. Limaye, T.S.R.Ch. Murthy, K. Sairam, A. Nagaraj, N.L. Soni, R.J. Patel, J.K. Chakravartty, Tribological properties of boron carbide in sliding against WC ball, Int. J. Refract. Met. Hard Mater. 51 (2015) 110-117.

14) P. Larsson, N. Axén, S. Hogmark, Tribofilm formation on boron carbide in sliding wear, Wear 236 (1-2) (1999) 73-80.

15) B.M Moshtaghioun, A.L. Ortiz, D. Gómez-García, A. Domínguez-Rodríguez, Toughening of super-hard ultra-fine grained $\mathrm{B}_{4} \mathrm{C}$ densified by spark-plasma sintering via SiC addition, $\mathrm{J}$ Eur. Ceram. Soc. 33 (8) (2013) 1395-1401.

16) B.M. Moshtaghioun, F.L. Cumbrera-Hernández, A.L. Ortiz, M. Castillo-Rodríguez, D. Gómez-García, Additive-free superhard B4C with ultrafine-grained dense microstructures, J. Eur. Ceram. Soc. 34 (3) (2014) 841-848.

17) B.M Moshtaghioun, A.L. Ortiz, D. Gómez-García, A. Domínguez-Rodríguez, Densification of $\mathrm{B}_{4} \mathrm{C}$ nanopowder with nanograin retention by spark-plasma sintering, J. Eur. Ceram. Soc. 35 (6) (2015) 1991-1998.

18) B.M. Moshtaghioun, D. Gómez-García, A. Domínguez-Rodríguez, A.L. Ortiz, Enhancing the spark-plasma sinterability of $\mathrm{B}_{4} \mathrm{C}$ nanopowders via room-temperature methylation induced purification, J. Eur. Ceram. Soc. 36 (11) (2016) 2843-2848. 
19) A.L. Ortiz, F. Sánchez-Bajo, V.M. Candelario, F. Guiberteau, Comminution of B 4 C powders with a high-energy mill operated in air in dry or wet conditions and its effect on the sparkplasma sinterability, J. Eur. Ceram. Soc. 37 (13) (2017) 3873-3884.

20) F. Rodríguez-Rojas, R. Moreno, F. Guiberteau, A.L. Ortiz, Aqueous colloidal processing of near-net shape B4C-Ni cermet compacts, J. Eur. Ceram. Soc. 36 (8) (2016) 1915-1921.

21) S.M. Hsu, M.C. Shen, Ceramic wear maps, Wear 200 (1-2) (1996) 154-175.

22) D. Bertagnoli, O. Borrero-López, F. Rodríguez-Rojas, F. Guiberteau, A.L. Ortiz, Effect of processing conditions on the sliding-wear resistance of $\mathrm{ZrC}$ triboceramics fabricated by spark-plasma sintering, Ceram. Int. 41 (10 Part B) (2015) 15278-15282.

23) V.M. Candelario, R. Moreno, F. Guiberteau, A.L. Ortiz, Enhancing the sliding-wear resistance of $\mathrm{SiC}$ nanostructured ceramics by adding carbon nanotubes, J. Eur. Ceram. Soc. 36 (13) (2016) 3083-3089.

24) E. Sánchez-González, O. Borrero-López, F. Guiberteau, A.L. Ortiz, Microstructural effects on the sliding-wear resistance of $\mathrm{ZrC}-\mathrm{MoSi}_{2}$ triboceramics fabricated by spark-plasma sintering, J. Eur. Ceram. Soc. 36 (13) (2016) 3091-3097.

25) O. Borrero-López, A. Pajares, P.J. Constantino, B.R. Lawn, A model for predicting wear rates in tooth enamel, J. Mech. Behav. Biomed. Mater. 37 (2014) 226-234.

26) S.-J. Cho, B.J. Hockey, B.R. Lawn, S.J. Bennison, Grain-size and $R$-curve effects in the abrasive wear of alumina, J. Am. Ceram. Soc. 72 (7) (1989) 1249-1252.

27) E. Ciudad, O. Borrero-López, A.L. Ortiz, F. Guiberteau, Microstructural effects on the sliding-wear resistance of pressureless liquid-phase-sintered $\mathrm{SiC}$ under diesel fuel, J. Eur. Ceram. Soc. 33 (4) (2013) 879-885. 
28) O. Borrero-López, A. Pajares, P.J. Constantino, B.R. Lawn, Mechanics of microwear traces in tooth enamel, Acta Biomater. 14 (2014) 146-153.

29) X. Wang, N.P. Padture, H. Tanaka, A.L. Ortiz, Wear-resistant ultra-fine-grained ceramics, Acta Mater. 53 (2) (2005) 271-277.

30) B.M. Moshtaghioun, D. Gomez-Garcia, A. Dominguez-Rodriguez, R.I. Todd, Grain size dependence of hardness and fracture toughness in pure near fully-dense boron carbide ceramics, J. Eur. Ceram. Soc. 36 (7) (2016) 1829-1834.

31) O. Borrero-López, A.L. Ortiz, F. Guiberteau, N.P. Padture, Effect of microstructure on sliding-wear properties of liquid-phase-sintered $\alpha$-SiC, J. Am. Ceram. Soc. 88 (8) (2005) 2159-2163.

32) O. Borrero-López, A.L. Ortiz, F. Guiberteau, N. Padture, Sliding-wear-resistant liquidphase-sintered $\mathrm{SiC}$ processed using $\alpha-\mathrm{SiC}$ starting powders, J. Am. Ceram. Soc. 90 (2) (2007) 541-545.

33) O. Borrero-López, A.L. Ortiz, F. Guiberteau, N.P. Padture, Microstructural design of sliding-wear-resistant liquid-phase-sintered SiC: an overview, J. Eur. Ceram. Soc. 27 (11) (2007) 3351-3357.

34) O. Borrero-López, A.L. Ortiz, A.D. Gledhill, F. Guiberteau, T. Mroz, L.M. Goldman, N.P. Padture, Microstructural effects on the sliding wear of transparent magnesium-aluminate spinel, J. Eur. Ceram. Soc. 32 (12) (2012) 3143-3149. 


\section{Figure Captions}

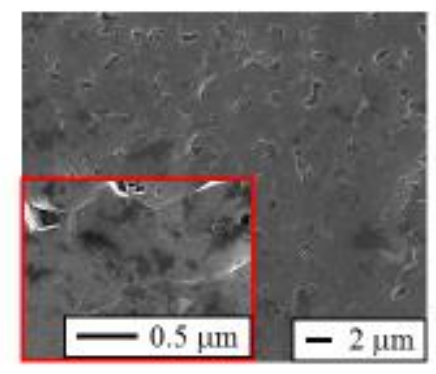

Ortiz et al.

Figure 1

Figure 1. Representative SEM images of the fracture surface of the $\mathrm{B}_{4} \mathrm{C}$ ceramic. The inset is a SEM image at higher magnification, showing more details. 


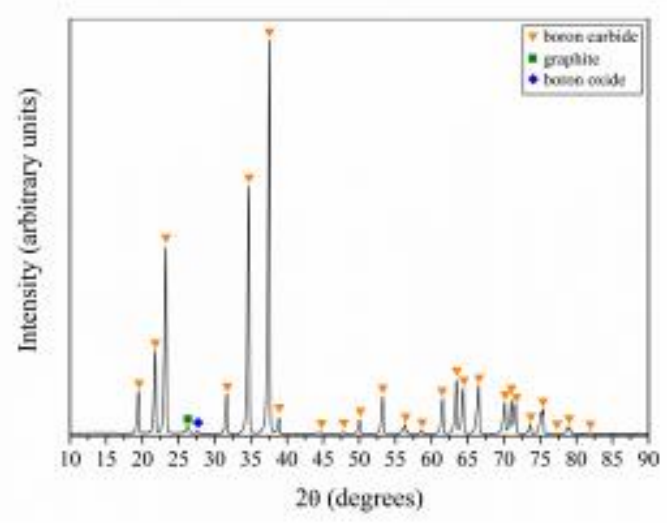

Ortiz et al.

Figure 2

Figure 2. XRD pattern of the $\mathrm{B}_{4} \mathrm{C}$ ceramic. Peak assignations are included. 


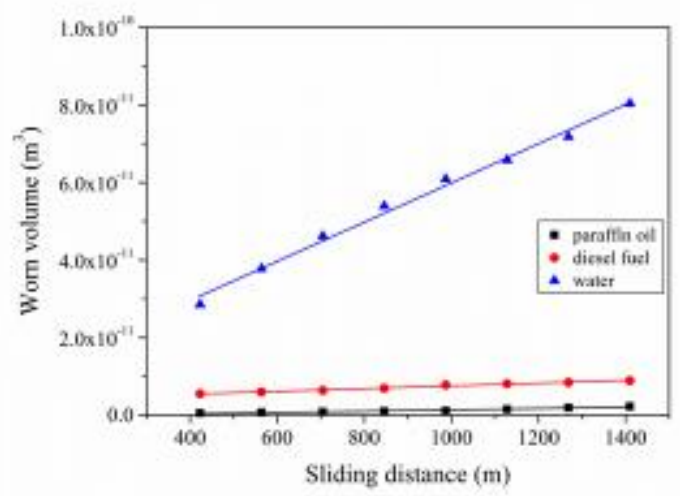

Figure 3. Wear curves for the $\mathrm{B}_{4} \mathrm{C}$ ceramic under sliding contact fully lubricated with water, diesel oil, and paraffin oil. Points are the experimental data. The solid lines are the linear fits to the data used to compute the corresponding SWRs. 


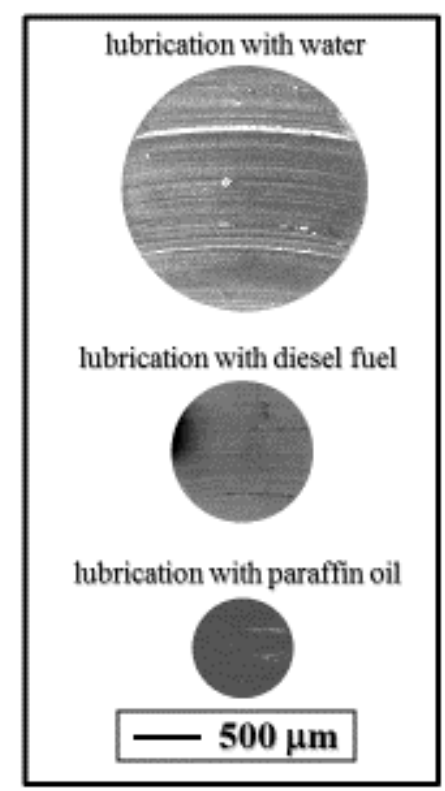

Ortiz at al.

Figure 4

Figure 4. Low-magnification SEM images of the wear scars for $\mathrm{B}_{4} \mathrm{C}$ ceramic at the end of the lubricated sliding-wear tests. The same scale bar is used intentionally to allow the straightforward visual comparison of the wear-scar sizes. 

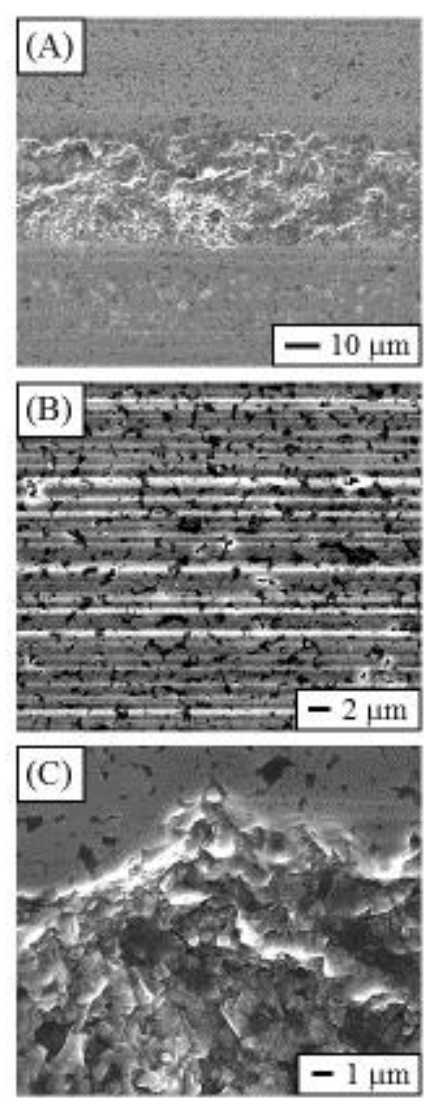

Figure 5. Representative SEM images of the damage within the wear scar of the $\mathrm{B}_{4} \mathrm{C}$ ceramic tested under water lubrication showing details of (A) the overall damage, (B) scratches, and (C) pitted regions. 

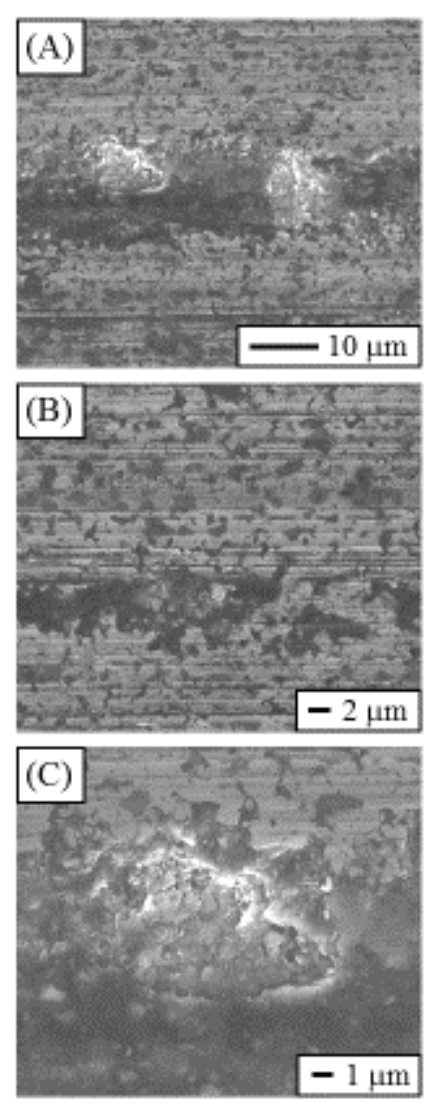

Figure 6. Representative SEM images of the damage within the wear scar of the $\mathrm{B}_{4} \mathrm{C}$ ceramic tested under diesel fuel lubrication showing details of (A) the overall damage, (B) scratches, and (C) pitted regions. 

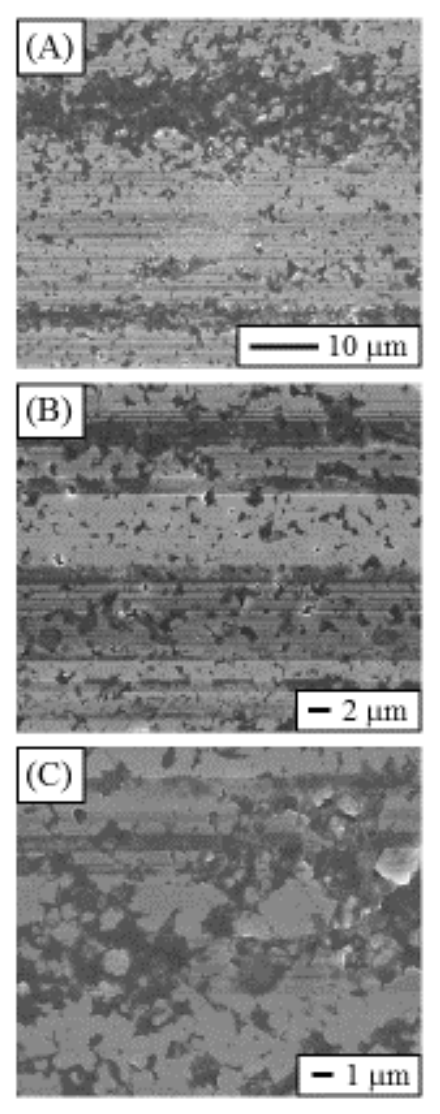

Oriz at al.

Figure?

Figure 7. Representative SEM images of the damage within the wear scar of the $\mathrm{B}_{4} \mathrm{C}$ ceramic tested under paraffin oil lubrication showing details of (A) the overall damage, (B) scratches, and (C) pitted regions. 